\title{
Performance Study of a Potentiometric Sensor Array for Lactic Proteins Analysis
}

\author{
Luís G. Dias ${ }^{1}$, Ana C.A. Veloso ${ }^{2,3}$, Adélio A.S.C. Machado ${ }^{4}$, António M. Peres ${ }^{1,5}$ \\ ${ }^{1}$ CIMO - Escola Superior Agrária, Instituto Politécnico de Bragança, Portugal, \\ peres@ipb.pt \\ ${ }^{2} D E Q B$ - Instituto Superior de Engenharia de Coimbra, Coimbra, Portugal, \\ ${ }^{3}$ IBB - Centre of Biological Engineering, University of Minho, Braga, Portugal, \\ ${ }^{4}$ LAQUIPAI - Departamento Química, Faculdade de Ciências, Universidade do Porto, Portugal, \\ ${ }^{5}$ LSRE - Laboratory of Separation and Reaction Engineering - Associate Laboratory LSRE/LCM, \\ Escola Superior Agrária, Instituto Politécnico de Bragança, Portugal
}

\begin{abstract}
Lactic proteins are complex biomolecules, possessing different molecular weights (from $19 \mathrm{kDa}$ up to $66 \mathrm{kDa}$ ), which can be used as biomarkers for detecting food adulterations. This study reports for the first time the evaluation of two potentiometric sensor arrays, one electronic tongue (ET) using only cross-sensitivity chemical sensors and a hybrid-ET containing ionic-selective and cross-sensitivity chemical sensors. Although both devices could detect and distinguish soluble and insoluble lactic proteins, namely bovine serum albumin and three main casein fractions (alpha-, beta- and kappa-), the inclusion of ionic-selective sensors increased the device performance $(100 \%$ of correct leave-oneout cross-validation classification for hybrid-ET against $94 \%$ for the ET) and reduced the number of sensors needed ( 5 for the hybrid-ET instead of 9 sensors used by the ET device). Finally, the results showed that with the hybrid-ET a second-order polynomial equation could be derived relating the measured potential of the aqueous solution and the logarithmic of the total casein concentration, with satisfactory determination coefficients $\left(R^{2}>0.99\right)$.
\end{abstract}

Key words: Potentiometric sensor array, cross-sensitivity chemical sensors, ionic-selective chemical sensors, lactic proteins

\section{Introduction}

The development of new chemical sensor arrays, as an efficient tool for the sensitive detection of target proteins, has gained growing industrial and academic interest. Nowadays, rapid and inexpensive sensing analysis is required in almost all research areas, namely in food analysis for the detection of traditional food adulterations [1]. Also, food-processing industry, such as cheese manufacturing, requires continuous monitoring and automation using real time analysis of critical quality parameters [2]. Full automation of the cheese manufacturing largely depends on the development of technologies for monitoring key milk constituents, like soluble and insoluble lactic proteins. However, the determination of the protein content is usually performed using conventional analytical techniques, based on the formation of colored complexes (protein assay kits) or ELISA methods [3]. Both techniques generally require multi-step sample pre-treatment procedures, expensive equipment and medium to high level of skill.

In this work, the performance of two electronic tongues (ET), constructed using a screenprinted technique, one containing 20 crosssensitivity chemical sensors and another hybrid-ET device using a set of 20 ionicselective and 20 cross-sensitivity chemical sensors were studied with the aim of differentiating soluble (bovine serum albumin, BSA) and insoluble proteins (caseins fractions, $\mathrm{CN}$ ), using standard aqueous solutions with different concentrations of the individual chemical species (BSA; $\alpha-, \beta-$ and $\kappa-C N$ ).

Finally, the response of the device, which possessed better performance, versus increased total casein concentrations in aqueous solutions was also evaluated.

\section{Materials and Methods}

The ET device consisted of 20 lipo-polymeric membranes applied to one-sensor array. Each membrane was prepared using approximately 
$31.8-32.3 \%$ of PVC as polymeric matrix, 64.8$65.1 \%$ of plasticizer compounds and $2.9-3.1 \%$ of sensor membrane additives (Table 1).

The hybrid-ET system contained 20 crosssensitivity sensors (prepared as described above) and 20 ionic-selective membranes, some of them were applied twice or thrice, when a non-crystalline visual aspect of the membrane was observed. Each of these ionicselective sensors was made using about 32.8$33.6 \%$ of PVC as polymeric matrix, $61.5-62.3 \%$ of plasticizer compounds and $4.7-5.1 \%$ of one sensor membrane additives (Table 2).

Tab. 1: Additives and plasticizers used for polymeric membranes preparation for the ET.

\begin{tabular}{|c|c|}
\hline $\begin{array}{c}\text { Membrane additive } \\
\text { substance }\end{array}$ & $\begin{array}{l}\text { Plasticizer } \\
\text { substance }\end{array}$ \\
\hline Octadecylamine & $\begin{array}{l}\text { Bis(1-butylpentyl) } \\
\text { adipate }\end{array}$ \\
\hline Oleyl alcohol & $\begin{array}{l}\text { Tris(2-ethylhexyl) } \\
\text { phosphate }\end{array}$ \\
\hline $\begin{array}{c}\text { Methyltrioctyl- } \\
\text { ammonium chloride }\end{array}$ & Dibutyl sebacate \\
\hline \multirow[t]{2}{*}{ Oleic acid } & $\begin{array}{c}\text { 2-Nitrophenyl- } \\
\text { octylether (2-NPOE) }\end{array}$ \\
\hline & $\begin{array}{c}\text { Dioctyl } \\
\text { phenylphosphonate }\end{array}$ \\
\hline
\end{tabular}

Tab. 2: Additives and plasticizers used for polymeric membranes preparation for the Hybrid-ET.

\begin{tabular}{|c|c|}
\hline $\begin{array}{l}\text { Membrane additive } \\
\text { substance }\end{array}$ & $\begin{array}{l}\text { Plasticizer } \\
\text { substance }\end{array}$ \\
\hline Octadecylamine & $\begin{array}{l}\text { Dibutyl } \\
\text { sebacate }\end{array}$ \\
\hline Bis(2-ethylhexyl)phosphate & $\begin{array}{l}\text { Dibutyl } \\
\text { sebacate }\end{array}$ \\
\hline Oleyl alcohol & $\begin{array}{l}\text { Dibutyl } \\
\text { sebacate }\end{array}$ \\
\hline $\begin{array}{l}\text { Methyltrioctylammonium } \\
\text { chloride }\end{array}$ & $\begin{array}{l}\text { Dibutyl } \\
\text { sebacate }\end{array}$ \\
\hline $\begin{array}{l}\text { Tridodecylmethylammonium } \\
\text { chloride }\end{array}$ & $\begin{array}{l}\text { Dibutyl } \\
\text { sebacate }\end{array}$ \\
\hline Oleic acid & $\begin{array}{c}\text { Dibutyl } \\
\text { sebacate }\end{array}$ \\
\hline Dibenzo-18-crown-6 & $\begin{array}{l}\text { Dibutyl } \\
\text { sebacate }\end{array}$ \\
\hline Mg ionophore & 2-NPOE \\
\hline Ca ionophore & 2-NPOE \\
\hline $\mathrm{Na}$ ionophore & 2-NPOE \\
\hline K ionophore & 2-NPOE \\
\hline Sulfate ionophore & 2-NPOE \\
\hline Nitrate ionophore & 2-NPOE \\
\hline Ammonium ionophore & 2-NPOE \\
\hline
\end{tabular}

All the polymeric membrane components were of analytical grade (from Fluka) and used as purchased. The multisensory system, together with a double junction $\mathrm{Ag} / \mathrm{AgCl}$ reference electrode, was connected to a multiplexer Agilent Data Acquisition/Switch Unit model 34970A. Agilent BenchLink Data Logger software installed in a PC computer was used to acquire the sensor signals. Measurements were performed at ambient temperature $\left(\approx 25^{\circ} \mathrm{C}\right)$.

The ability of the multi-sensor devices to recognize and discriminate different lactic proteins (soluble and insoluble) was evaluated using standard aqueous solutions with different concentrations of BSA, $\alpha-, \beta$ - and $\kappa-\mathrm{CN}\left(10^{-6}\right.$ to $\left.10^{-5} \mathrm{~g} / \mathrm{L}\right)$, which were of analytical grade and (from Sigma). A linear discriminant analysis (LDA) was used as a classification supervised learning technique. A forward stepwise technique was applied for variable selection, which allowed identifying the significant variables (sensor signals) among the entire set of sensors signal profiles recorded by the devices (ET and hybrid-ET). To avoid overoptimistic data modulation, a leaving-oneout cross-validation procedure was carried out to assess the model performance. The LDA statistical analysis was performed at a $5 \%$ significance level using the SPSS and SYSTAT software.

Finally, the typical sensors responses of the hybrid-ET device, to increasing concentrations of total casein in aqueous solutions, were also recorded.

\section{Results and Discussion}

The results (Figures 1 and 2) showed that the signals profiles of the 2 potentiometric devices built (ET and hybrid-ET) together with LDA technique, were successful in discriminating the 4 lactic proteins, which have different molecular weights $(\sim 66,23,24$ and $19 \mathrm{kDa}$ for BSA; $\alpha$-, $\beta$ - and $\kappa-\mathrm{CN}$, respectively).

For the ET device, 9 cross-sensitivity chemical sensors were selected. The respective signals profile allowed a $94 \%$ of correct classification for the leave-one-out cross-validation procedure, using 3 statistically significant discriminant functions (that explained $100 \%$ of the total variance). For the hybrid-ET device, only 5 sensors were used (being 2 ionicselective sensors) by 2 statistically significant discriminant functions (that explained $99.9 \%$ of the total variance) allowing $100 \%$ of correct cross-validation classification of the lactic proteins aqueous solutions. So, the results achieved clearly pointed out that the inclusion of ionic-selective sensors enhanced the classification performance of the potentiometric 
device and reduced the total number of sensors required.

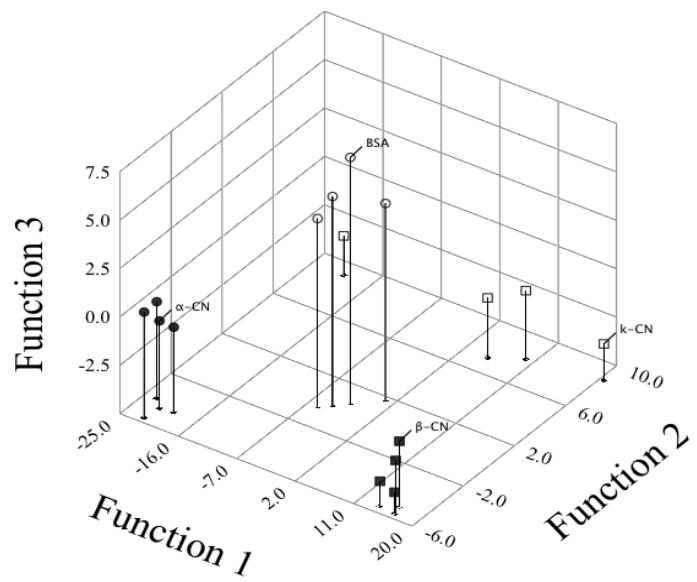

Fig. 1. ET device: $L D A$ of aqueous solutions $\left(10^{-6}\right.$ $10^{-5} \mathrm{~g} / \mathrm{L}$ ) of BSA, $\alpha-C N, \beta-C N$ and $\kappa-C N$; based on the signals profile of 9 cross-sensitivity chemical sensors.

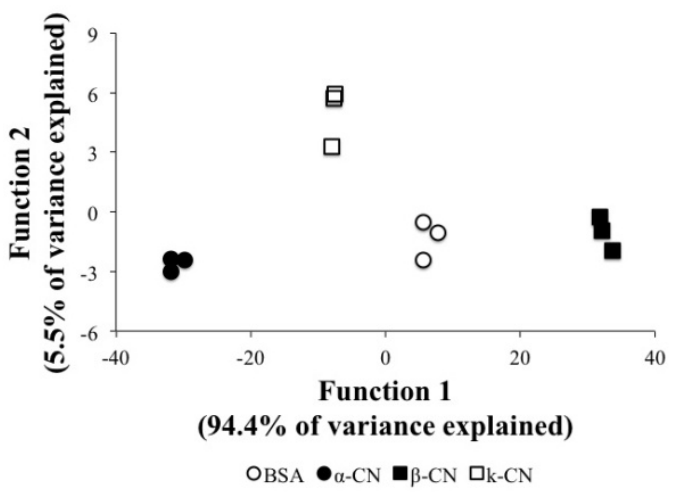

Fig. 2. Hybrid-ET device: LDA of aqueous solutions $\left(10^{-6}-10^{-5} \mathrm{~g} / \mathrm{L}\right)$ of $B S A, \alpha-C N, \beta-$ casein $\beta-C N$ and $\kappa-C N$; based on the signals profile of 2 ionicselective and 3 cross-sensitivity chemical sensors.

Since the hybrid-ET device showed a better global performance, its ability to quantify the total casein amount in aqueous standard solutions was evaluated. For several of the sensors tested (ionic-selective and crosssensitivity chemical sensors) a polynomial response of the sensors' signal to additions of increasing amounts of total casein was verified $\left(R^{2}>0.99\right)$. This fact shows that the multi-sensor system developed in the present study can be used to quantify total casein in aqueous solutions, in the dynamic range tested (between $10^{-6}$ and $\left.10^{-5} \mathrm{~g} / \mathrm{L}\right)$. Figure 3 shows a typical example of the sensor signal response towards total casein concentration.

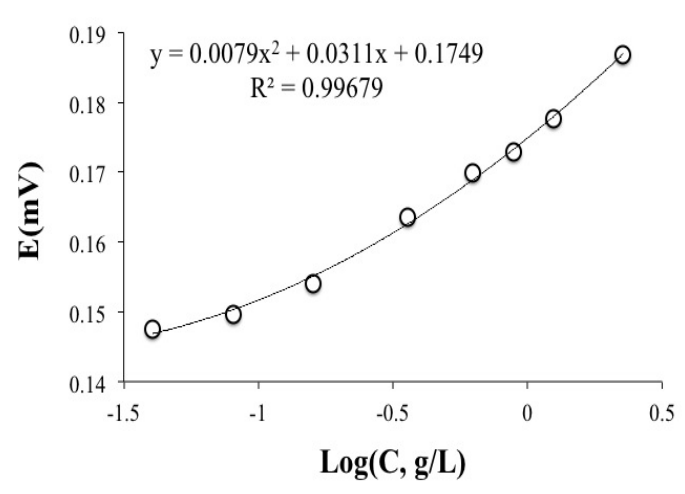

Fig. 3. Typical sensor response (hybrid-ET device) to increasing concentrations of total casein in aqueous solutions.

\section{Conclusions}

The simultaneous use of ionic-selective sensors and cross-sensitivity chemical sensors in a hybrid-ET enhanced the capability of the potentiometric device to differentiate lactic proteins that have different molecular weights. Also, due to the positive synergetic effect observed between ionic-selective and crosssensitivity sensors, the number of sensors required for the correct classification of aqueous solutions of lactic proteins according to their type was approximately reduced to half of those that would be necessary if only crosssensitivity chemical sensors were used. Finally, the signals profiles of both ionic-selective and of cross-sensitivity chemical sensors showed that it was possible to quantify the amount of total casein in aqueous solutions.

In conclusion, the preliminary results reported in this work show that the simultaneous use of ionic-selective and cross-sensitivity chemical sensors, within the same potentiometric sensor array, has good analytical prospects within the field of protein analysis.

Finally, to the best of the authors' knowledge, this is the first time that a procedure, based on a hybrid-ET, is successfully applied to discriminate lactic proteins and to estimate total casein amounts in aqueous solutions.

\section{Acknowledgements}

This work was partially supported by project PEst-C/EQB/LA0020/2011, financed by FEDER through COMPETE - Programa Operacional Factores de Competitividade and by FCT Fundação para a Ciência e a Tecnologia.

\section{References}

[1] L.G. Dias, A.M. Peres, A.C.A. Veloso, F.S. Reis, M. Vilas Boas, A.A.S.C. Machado, An electronic tongue taste evaluation: Identification of goat milk 
adulteration with bovine milk, Sensors and Actuators B 136, 209-217 (2009); doi:

10.1016/j.snb.2008.09.025

[2] C.C. Fagan, M. Castillo, F.A. Payne, C.P. O'Donnell, M. Leedy, D.J. O'Callaghan, Novel Online Sensor Technology for Continuous Monitoring of Milk Coagulation and Whey Separation in Cheesemaking, Journal of Agricultural and Food Chemistry 55: 8836-8844 (2007); doi: 10.1021/jf070807b

[3] J. Rick, T.-C. Chou, Amperometric protein sensor - fabricated as a polypyrrole, polyaminophenylboronic acid bilayer, Biosensors and Bioelectronics 22: 329-335 (2006); doi:10.1016/j.bios.2006.04.007 